Article

\title{
Application of Vegetal Oils in Developing Bioactive Paper-Based Materials for Food Packaging
}

\author{
Anamaria Irimia, Elena Stoleru*(D), Cornelia Vasile (D), Adrian Bele (D) and Mihai Brebu (D) \\ Romanian Academy, “Petru Poni” Institute of Macromolecular Chemistry, Grigore Ghica Voda Alley, Nr. 41A, \\ 700487 Iași, Romania; anamaria.sdrobis@icmpp.ro (A.I.); cvasile@icmpp.ro (C.V.); bele.adrian@icmpp.ro (A.B.); \\ bmihai@icmpp.ro (M.B.) \\ * Correspondence: elena.paslaru@icmpp.ro; Tel.: +40-332-880-220
}

Citation: Irimia, A.; Stoleru, E.; Vasile, C.; Bele, A.; Brebu, M. Application of Vegetal Oils in Developing Bioactive Paper-Based Materials for Food Packaging. Coatings 2021, 11, 1211. https:// doi.org/10.3390/coatings11101211

Academic Editor: Fengwei (David) Xie

Received: 31 August 2021

Accepted: 28 September 2021

Published: 2 October 2021

Publisher's Note: MDPI stays neutral with regard to jurisdictional claims in published maps and institutional affiliations.

Copyright: (c) 2021 by the authors. Licensee MDPI, Basel, Switzerland. This article is an open access article distributed under the terms and conditions of the Creative Commons Attribution (CC BY) license (https:// creativecommons.org/licenses/by/ $4.0 /)$.
Abstract: A major disadvantage of conventional food packaging materials is the difficulty in disposal and recycling, due to their high stability to environmental and thermal stress. The trend now is to develop new eco-friendly food packaging that can substitute fossil fuel derived materials. Cellulose, the main constituent of paper-based food packages, is a favorable starting material for such purpose. In this study we present a new method to obtain bioactive paper based materials suitable for food packaging applications. By combining eco-friendly activation processes (cold plasma or gamma irradiation) and bioactive plant oils (clove essential oil and rosehip seeds vegetal oil) for modification of kraft paper, new materials with antioxidant and antibacterial activity were obtained. The oilloaded bioactive paper based materials presented increased hydrophobicity (from $97^{\circ}$ contact angle in the case of kraft paper to $115^{\circ}$ for oil-loaded sample) and decreased water adsorption (a onequarter decrease). Due to various interactions with the functional groups of plant oils, the modified kraft paper presents different antibacterial and antioxidant properties. Essential clove oil imprinted higher antioxidant activity (owing to the high content in eugenol and eugenol acetate phenolic compounds) and was more efficient in reducing the bacterial growth on fresh beef meat and on fresh curd cheese. The cold pressed rosehip seeds oil acted as aslightly better antibacterial agent against Listeria monocytogenes (+), Salmonella enteritidis (-) and Escherichia coli (-) bacterial strains. Thus, the newly developed bioactive paper could be used as effective packaging material that can help preserving food quality for longer time.

Keywords: active food packaging; vegetal oils; radiation-induced surface activation; food safety/testing; kraft paper

\section{Introduction}

Nowadays, the consumers manifest an increasing interest towards food quality and safety, with rejection attitude against synthetic additives. However, preservation methods are necessary to reduce food spoilage. In this context, usage of natural additives and inclusion of preservatives into packages instead of adding them directly to food are approaches of great interest. These leaded to the concept of active food packaging [1]. The main function of active food packaging is to keep the content clean and sterile from production to transport and storage, maintaining at the same time the quality and sensorial properties. Therefore, various kinds of packaging materials are available or are developed in order to protect the food products, and their selection depends on the type of the foodstuff [2]. Various microorganisms can be naturally present on food or can appear by contamination. Among them, spoilage microorganisms lead to depreciation, thus limiting the shelf life, while pathogenic microorganisms have no alteration effect on food but they are harmful to humans, their presence on food limiting the safe life [3]. In order to develop active food packaging, various natural additives (antimicrobials, antioxidants, coloring agents or sweeteners), derived from plants, animals or microorganisms are used [4,5]. Introducing 
antimicrobial agents in packaging materials can inhibit microbial growth, prolonging the time in which food maintains its properties [6]. In food packaging field, besides the efforts made in creating supplementary active functions, a strong emphasis is placed also on the need to develop new eco-friendly materials in order to replace petroleum-based polymers and aluminum layers. In this sense, the usage of polysaccharide-based materials represents a promising approach. In general, paper and cellulose-based materials are extensively used in wrapping and food packaging, offering the advantage of natural origin and facile biodegradation or recyclability $[7,8]$.

Among the natural additives vegetal oils have various suitable properties to be applied in food related applications. Essential oils are lipophilic liquids extracted from various parts of plants; they have complex composition that gives antioxidant and antimicrobial properties. In the scientific literature is largely presented their antimicrobial activity against various microorganisms. Because of the hydrophobicity of their components, essential oils pass easily through bacterial cell membrane, and affect the mechanisms of molecular transport leading to the inactivation of cells [9,10]. Clove essential oil proved efficient antimicrobial activity against numerous microorganisms such as gram positive and gram negative bacteria (e.g., Staphylococcus, Streptococcus, Listeria, Escherichia coli, Salmonella, Pseudomonas aeruginosa) and fungi (e.g., Aspergillus, Penicillium) [11,12]. Tests on the oxygen radical absorption capacity (ORAC) showed a very strong antioxidant action for the essential oil from clove, of 3-10 times higher than from other essential oils [13].

Plant oils extracted mainly from seeds but also from other parts of plants, have many benefits in different applications such as nutrition [14,15], medicine [16,17], cosmetics [18], and bio-fuels $[19,20]$. Seeds oils consists mainly of saturated and unsaturated fatty acids that induce their lipophilic character, while minor compounds such as phenolic derivatives and flavonoids impart the antioxidant and antimicrobial activity [21,22]. The antimicrobial mechanism of plant oils on gram negative bacteria is based mainly on disintegration of the cells external membrane, followed by the release of lipopolysaccharides and decreased permeability of cytoplasmic membrane to adenosine triphosphate, which represent the vital energy-carrying molecule in cells of all living organisms $[23,24]$. The oil obtained from seeds of wild roses (Rosa canina L.), commonly known as rosehip oil, is rich in many beneficial compounds, mainly unsaturated fatty acids (content $>90 \%$ ), and phenolic derivatives, tocopherols, carotenoids, etc. The composition of the oil determines its bioactive properties, namely strong antioxidant potential and fine antimicrobial activity [22,25]. Many materials shows fine bulk properties but have limitations in terms of lack of functionality. In this context, the methods that allow only surface modification represent an attractive way to impart functionality to a material, otherwise inert. These methods are divided into two categories, namely physical and chemical. First category includes gas plasma and gamma radiation technologies, and is usually preferred in various applications [26]. The main advantages of these methods are represented by their eco-friendly toxic and corrosive solvents, and safety [27], and supplementary for plasma the fact that it acts only on the surface's outermost layers [28-30]. The mechanism of action of ionizing radiation on polymeric materials involves generation of radicals that may react with each other, with the atmospheric oxygen or with other compounds, and which may lead to polymerization, cross-linking, grafting or degradation processes [31]. Several factors, such as the chemical structure of the polymer, the radiation dose and surrounding medium of irradiation influence the type of the modification that occurs in material [32]. In general, low doses of gamma radiation $(2.5-25 \mathrm{kGy})$ is applied for sterilization and preservation purposes on food $[33,34]$.

In our previous researches physical modification approaches, namely plasma or $\gamma$ irradiation, were addressed to efficiently functionalize various polymeric substrates such as cellulose/chitin mixed fibers [30], poly(lactic acid) [35,36] to allow immobilization of different bioactive agents (e.g., eugenol, clove essential oil, grape seeds oil, rosehip seeds oil, argan oil, etc.). 
Taking into considerations the above mentioned aspects, the goal of this research was to obtain new paper based eco-friendly materials, with antibacterial and antioxidant properties induced by clove essential oil or rosehip vegetal oil, suitable for food packaging. The novelty of this work consists in comparative discussions on two surface activation techniques (cold plasma treatment and gamma irradiation) and two bioactive plant oils of different nature, one essential oil and one cold-pressed oil, (clove essential oil and rosehip seeds vegetal oil) and on the antimicrobial effects that they induce to kraft paper, both in vitro, on Listeria monocytogenes (+), Salmonella enteritidis (-) and Escherichia coli (-) bacterial strains, and in vivo, on fresh curd cheese and beef meat. Moreover, in this work we evaluated the obtained biocomposites for changes in the structural and morphological properties, hydrophobicity, water adsorption, antioxidant and microbiological activity. The investigations proved that the new obtained bio-functionalized materials can help control foodborne pathogens in foodstuffs, leading to extended shelf-life, thus being suitable for food packaging applications.

\section{Materials and Methods}

\subsection{Materials}

Commercially available unbleached kraft paper $(\mathrm{P})$, with $0.64 \mathrm{~g} / \mathrm{cm}^{3}$ density and 100 microns thickness, appropriate for food packaging, was acquired from Adi Center SRL, Iasi, Romania. Two activation and coupling agents namely 1-ethyl-3-(3-dimethylaminopropyl) carbodiimide hydrochloride (EDC) and N-hydroxysuccinimide (NHS) were purchased from Sigma-Aldrich (Steinheim, Germany). Methanol and chloroform used as solvents were of analytical grade and were purchased from Chemical Company, Iasi, Romania.

Clove essential oil (CEO), acquired from Fares, Orastie, Romania, and rosehip seeds cold pressed vegetal oil (RVO), acquired from S.C. Herbavit S.R.L, Iasi, Romania, were chosen for functionalization of kraft paper. Selection was based on their high content of antioxidant compounds, as presented in our previous works $[37,38]$.

\subsection{Kraft Paper Functionalization}

Surface activation of commercial kraft paper was achieved by two methods, namely plasma treatment and $\gamma$-irradiation.

A mild high-frequency cold plasma (CPA) was obtained at $1.3 \mathrm{MHz}$ under $0.5 \mathrm{mbar}$ vacuum and $30 \mathrm{~W}$ discharge power, using air as discharge gas. Samples were placed between two $18 \mathrm{~cm} \times 21 \mathrm{~cm}$ rectangular electrodes placed at $6.5 \mathrm{~cm}$ apart, and exposed for $15 \mathrm{~min}$. A more detailed description of the cold-plasma experimental set-up can be found in our previous work [29].

Activation by $\gamma$-irradiation was performed using an M-38 GAMMATOR (Best Theratronics, Ottawa, ON, Canada), equipped with a ${ }^{137} \mathrm{Cs}$ source, in air, at room temperature, under a $0.4 \mathrm{kGy} / \mathrm{h}$ dose rate, achieving a $20 \mathrm{kGy}$ dose of $\gamma$-irradiation of the material. Samples were covered with aluminum foil and were continuously rotated for homogenous irradiation.

The statistical distributed active centers, formed on the surface of the materials after plasma treatment or $\gamma$-irradiation, have high reactivity for creation of new bonds [39]. Hence, they are converted by air exposure into reactive functional groups able to chemically react with the bioactive compounds used for functionalization.

After activation, the kraft paper was immersed in $10 \mathrm{wt} . \%$ methanol solution of clove essential oil or in $10 \mathrm{wt} . \%$ chloroform solution of rosehip seeds vegetal oil and left under mechanic stirring for $60 \mathrm{~min}$. The solutions of plant oils also contained a mix of the two chemical coupling agents, namely EDC and NHS, in order to increase the activation efficiency and to enhance immobilization onto paper substrate of the bioactive principles through chemical bonds.

The obtained materials were dried at $60{ }^{\circ} \mathrm{C}$, and then washed with methanol or chloroform to remove the physically adsorbed, unreacted compounds from the plant oils. 
Final drying was performed at $40{ }^{\circ} \mathrm{C}$ in a vacuum oven before further analysis. In Table 1 are listed the samples codes and their descriptions.

Table 1. Codes and description of studied samples based on kraft paper (P).

\begin{tabular}{lll}
\hline Sample Code & Activation Procedure & Type of Oil \\
\hline $\mathrm{P}$ & - & - \\
$\mathrm{P} / \mathrm{CPA} / \mathrm{CEO}$ & cold air plasma & clove essential oil \\
$\mathrm{P} / \mathrm{CPA} / \mathrm{RVO}$ & cold air plasma & rosehip seeds vegetal oil \\
$\mathrm{P} / 20 \mathrm{kG} / \mathrm{CEO}$ & $20 \mathrm{kGy} \gamma$-irradiation & clove essential oil \\
$\mathrm{P} / 20 \mathrm{kGy} / \mathrm{RVO}$ & $20 \mathrm{kGy} \gamma$-irradiation & rosehip seeds vegetal oil \\
\hline
\end{tabular}

\subsection{Investigation Methods}

\subsubsection{FT-IR Spectroscopy}

The Fourier Transform Infrared spectra were recorded in Attenuated Total Reflection mode (ATR-FTIR) at $4 \mathrm{~cm}^{-1}$ resolution with 64 scans, using a VERTEX 70 spectrometer (Bruker Optics, Ettlingen, Germany), in absorbance mode. Each spectrum represents the average of three recordings.

\subsubsection{Scanning Electron Microscopy}

Morphology evaluations were performed with a scanning electron microscope equipped with energy dispersive X-ray modulus (SEM/- EDAX) model QUANTA 200 (FEI Company, OR, USA), without any further treatments, at $1000 \mathrm{X}$ magnification. EDAX results are expressed as the average of three measurements, for different sample zones, with their corresponding standard deviation.

\subsubsection{Contact Angle Measurements}

Water contact angle measurements were used to determine how plant oils affected the hydrophobicity of paper surface. If the contact angle of water is larger than $90^{\circ}$ the surface is considered hydrophobic, while for contact angles smaller than $90^{\circ}$ the surfaces are categorized as hydrophilic. Complete wettability is observed when contact angle is $0^{\circ}$. Thus, a determination of the contact angle is very important and has practical application in the food industry [40].The wettability of surfaces was determined by static contact angle measurements performed on a CAM-200 goniometer from (KSV Instruments Ltd, Helsinki, Finland). The water contact angle was determined by the sessile drop method, at room temperature and controlled humidity, within $5 \mathrm{~s}$ after placing $2 \mu \mathrm{L}$ drops of liquid on sample's surface. At least 10 measurements were performed on a sample and results from three different samples were considered for statistical determination of the final average value.

\subsubsection{Dynamic Water Vapors Sorption Analysis}

The water vapors sorption capacity was measured in dynamic regime at $25^{\circ} \mathrm{C}$, using an IGAsorp equipment (Hiden Analytical, Warrington, UK). The vapor pressure was increased and decreased in 10\% humidity steps, between 0 and $90 \%$ relative humidity range for sorption and desorption, respectively, after equilibrium time between 10 and 20 min established based on preliminary tests using as criterion the mass variation of less than $1 \%$ in $90 \mathrm{~s}$.

\subsubsection{DPPH Radical Scavenging Assay}

The radical scavenging activity (RSA) of modified kraft paper was evaluated using 2,2-diphenyl-1-picrylhydrazyl (DPPH). DPPH is a stable free radical with a violet color that is reduced under the action of proton donating compounds, to a light yellow color and this change can be monitored at $517 \mathrm{~nm}$. Briefly, known weighted amounts of samples were placed into $10 \mathrm{~mL}$ volumes of methanol and shaken overnight. Known volumes of 
the resulted solution were mixed with $6 \mathrm{~mL} 0.05 \mathrm{mM}$ DPPH in methanol and left in dark for $30 \mathrm{~min}$ in closed vials before recording the UV absorbance.

Equation (1) was used to calculate the radical scavenging activity:

$$
\% \text { RSA }=100 \times\left(1-\frac{A_{\text {sample }}}{A_{\text {control }}}\right)
$$

where: $A_{\text {sample }}$ represents the absorbance of the sample solution and $A_{\text {control }}$ represents the absorbance of DPPH solution with unmodified sample.

The IC50 value is defined as the concentration at which \%RSA reached the $50 \%$. Methanolic extracts with various concentrations were prepared as presented above and linear regression analysis of the corresponding \%RSA values was used to calculate the IC50.

\subsubsection{In Vitro Antibacterial Activity}

Antibacterial tests were performed on three different American Type Culture Collection (ATCC, Rockville, MD, USA) bacterial strains, namely Escherichia coli-ATCC 25922 and Salmonella enteritidis-ATCC 14028 (gram negative) and Listeria monocytogenes-ATCC 7644 (gram positive), according to specific standard methods. The procedure mainly involves sterilization (for $20 \mathrm{~min}$ in autoclave at $110^{\circ} \mathrm{C}$ and 0.5 bars) of the samples, contamination by seeding $0.1 \mathrm{~mL}$ bacterial cultures using sterile swabs on samples surface, inoculation and incubation for 24 and $48 \mathrm{~h}$ at $37^{\circ} \mathrm{C}$, followed by colony counting. In the case of E. coli identification was performed by coloration with 5 -bromo-4-chloro-3-indolyl- $\beta$-D-glucuronide. Listeria monocytogenes was identified using the $\beta$-haemolysis test, while Salmonella was counted by specific plate count Xylose Lysine Deoxycholate agar (XLD agar) method.

\subsubsection{In Vivo Microbiological Assessment on Food}

We aim to determine the effect of kraft paper modified with plant oils packaging materials against the unmodified paper, the microorganism grow on fresh food, in usual storage conditions. Specific microbiological examinations follow the changes occurred at 24 and $48 \mathrm{~h}$ after food contact with tested papers. The modified papers with proved antibacterial properties were tested in aseptic laboratory conditions on a traditional dairy product (fresh curd cheese) and on fresh beef meat (originating from one local slaughter house delivered no later than $4 \mathrm{~h}$ after slaughter), both having short shelf life.

The coli group bacteria are indicators of the hygienic quality of white cheeses. Most often, the microbiological spoilage of white cheese during its storage is caused by yeast and molds. Therefore, in this study we monitored the growth of those groups of microorganisms in stored white cheese packed in contact with the plant oil modified papers. The examined white cheese was characterized by low contamination with coli group bacilli, the number of those bacteria in fresh control sample being less than $10 \mathrm{CFU} / \mathrm{g}$.

Meat consists mainly in protein and fats. Healthy animal's muscles don't contain fungi or bacteria, but meat might be contaminated when animals are slaughtered, or along the processing chain. The number of harmful organisms on the meat immediately after slaughter represents a major factor in determining the shelf-life. The surface of beef carcasses can contain from 10 to $10^{7} \mathrm{cfu} / \mathrm{cm}^{2}$ bacteria colonies, most of them being psychrotrophic bacteria. Cutting and grinding meat can increase the microbial load, since the exposed surface area is considerably increased. Yeasts and molds grow relatively slowly on fresh meat and do not compete well with bacteria. Therefore, they are a minor component of spoilage flora [41].

The kraft papers functionalized with plant oils were cut in square pieces of $4 \mathrm{~cm}^{2}$ size and placed in sterile Petri dishes. Food cubic samples aseptically cut to $1 \mathrm{~cm}^{3}$ were placed in the center of the paper pieces, and the Petri dishes were sealed and refrigerated at $7{ }^{\circ} \mathrm{C}$. Samples were brought to room temperature after 24 and $48 \mathrm{~h}$, respectively, for analysis. The $\mathrm{pH}$ on the bottom surface of the food samples was checked using indicator paper. The surface of the kraft papers on which food samples were stored was wiped off with a sterile swab that was then immersed in a test tube with $10 \mathrm{~mL}$ of physiological serum. Volumes 
of $1 \mathrm{~mL}$ from the formed suspensions were seeded in two autoclaved and cooled Petri dishes containing plate count agar (PCA). After solidification, the plates were thermostated at $30^{\circ} \mathrm{C}$ for $72 \mathrm{~h}$ according to SR ISO $4833 / 2014$ [42]. Microbiological examinations and interpretation of results were performed according to SR EN ISO 7218/2014 [43].

Evolution of microorganisms' development on food was also evaluated on cheese by monitoring the oxygen consumption through respirometry assays performed on an ER12 ECHO Instruments Respirometer (ECHO, Slovenske Konjce, Slovenia).

\section{Results and Discussion}

\subsection{ATR-FTIR Spectra Results}

Surface modification of kraft paper with bioactive compounds after plasma discharge or gamma irradiation revealed changes in the $3800-2700 \mathrm{~cm}^{-1}$ region, assigned to the $\mathrm{OH}$ and $\mathrm{CH}$ stretching vibrations and in the "fingerprint" $1500-600 \mathrm{~cm}^{-1}$ region of the FTIR spectra, which corresponds to stretching or deformation vibrations of different groups Figure 1.
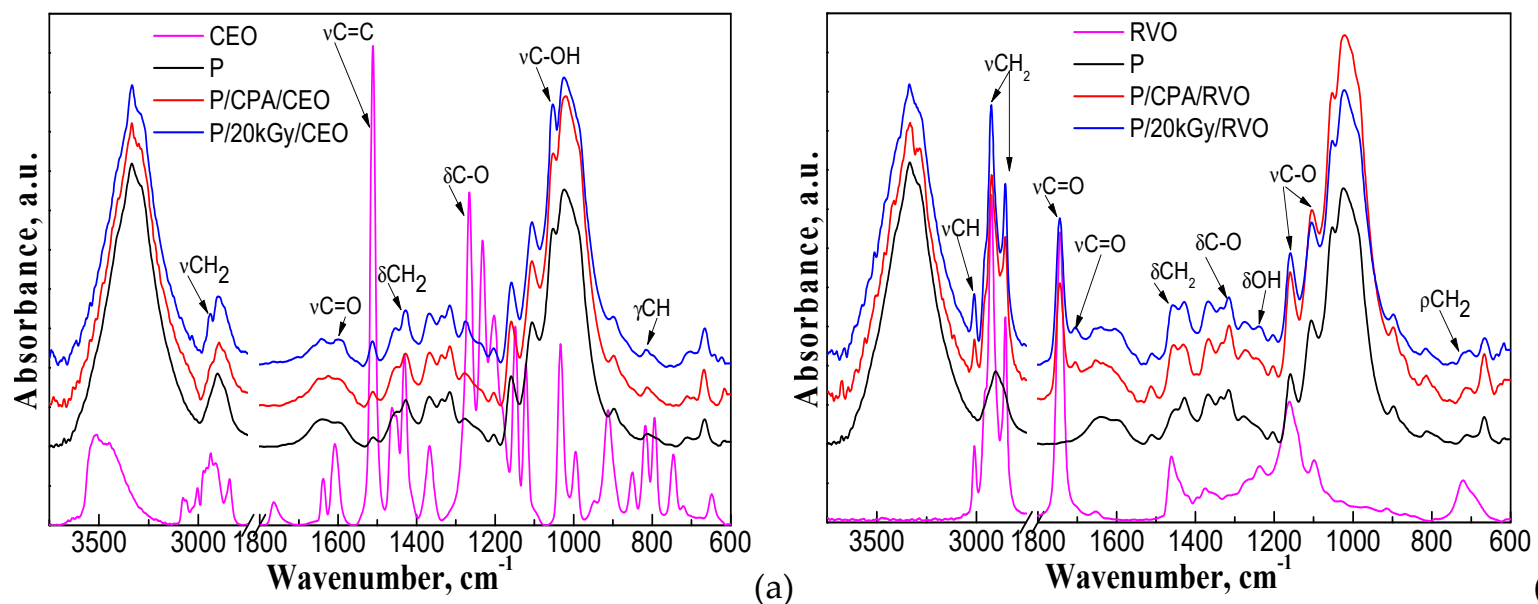

(b)

Figure 1. The infrared spectra of kraft paper activated by plasma or gamma irradiation and modified with clove essential oil (CEO) (a) and rosehip seeds vegetal oil (RVO) (b).

In case of CEO modified paper, new peaks or shoulders were observed (Figure 1a), namely at: 2940, $2945 \mathrm{~cm}^{-1}$ ( $\mathrm{CH}_{2}$ group, stretching vibrations from aromatic moiety); 1510 , $1513 \mathrm{~cm}^{-1}$ (aromatic C-C stretching); 1274, $1276 \mathrm{~cm}^{-1}$ (-C-O-C group, C-O deformation vibrations); $811,813 \mathrm{~cm}^{-1}$ (CH stretching vibrations). In addition, an increase in peak intensity, due to the overlapped vibration bands of kraft paper substrate and CEO was observed at $1600-1595 \mathrm{~cm}^{-1}$ (COOH group, $\mathrm{C}=\mathrm{O}$ stretching vibrations); $1427,1428 \mathrm{~cm}^{-1}$ (- $\mathrm{CH}_{2}-$ deformation vibrations); $1240 \mathrm{~cm}^{-1}(\mathrm{OH}$, deformation vibrations, from $\mathrm{COOH}$ group); $1051 \mathrm{~cm}^{-1}$ (-C-O-C group, $\mathrm{C}-\mathrm{O}$ stretching vibrations).

In case of RVO modified paper, new peaks or shoulders were observed (Figure 1b), namely at: $3011-3009 \mathrm{~cm}^{-1}$ (CH group stretching vibrations); $2851 \mathrm{~cm}^{-1}\left(\mathrm{CH}_{2}\right.$ stretching vibrations); $1746-1744 \mathrm{~cm}^{-1}$ (COOH group, $\mathrm{C}=\mathrm{O}$ stretching vibrations); $1460 \mathrm{~cm}^{-1}\left(-\mathrm{CH}_{2}-\right.$ deformation vibrations); shoulder at $1315 \mathrm{~cm}^{-1}$ (C-O deformation vibrations from $\mathrm{C}-\mathrm{OH}$ group); shoulder at $1001-987 \mathrm{~cm}^{-1}$ (C-O valence vibrations). Also, an increase in peak intensity, due to the overlapped vibration bands of kraft paper substrate and RVO was observed at $2924 \mathrm{~cm}^{-1}\left(\mathrm{CH}_{3}\right.$ group, stretching vibrations); $1237 \mathrm{~cm}^{-1}$ (C-O stretching from ester group) $1160-1105 \mathrm{~cm}^{-1}$ (C-O-C, CO stretching vibration), and $715 \mathrm{~cm}^{-1}\left(\mathrm{CH}_{2}\right.$ group, in plane deformation vibration). In addition, a new band is observed at $\sim 1705 \mathrm{~cm}^{-1}$ ( $C=\mathrm{O}$ stretching, amide I group). This could be explained by the conversion of amine groups created on the kraft paper surface (by air plasma and $\gamma$-irradiation in air) into amide groups by reaction with RVO, facilitated by the coupling agents. 
In general, polar and reactive groups such as hydroxyl, carboxyl, (hydro)peroxides, esters and amine are formed at the surface of polymeric materials by air plasma treatment $[44,45]$. We suppose that similar behavior occurs in case of $\gamma$-irradiation, which was also performed in air, and it is characterized by higher energy radiation and deeper penetration than plasma treatment.

Based on the results obtained, we can establish that the modification took place after activation both in plasma discharge and in gamma irradiation. It seems that the efficiency was higher for sample modified with rosehip vegetal oil compared with clove essential oil.

The variation in the surface modification corresponds with the composition of plant oils. In case of clove essential oil the main compounds are eugenol ( $86 \%)$, eugenol acetate $(\sim 8 \%)$, and $\beta$-caryophyllene $(\sim 4.5 \%)$ [46], while rosehip seeds vegetal oil consists mainly in unsaturated fatty acids: linoleic acid $(\sim 54 \%), \alpha$-linolenic acid $(\sim 22 \%)$ and oleic acid $(\sim 19 \%)$ [47].

\subsection{SEM Results}

The surface morphology of kraft paper modified with clove essential oil and rosehip seeds vegetal oil after activation by plasma exposure or by $\gamma$-irradiation was analyzed by SEM-Figure 2.
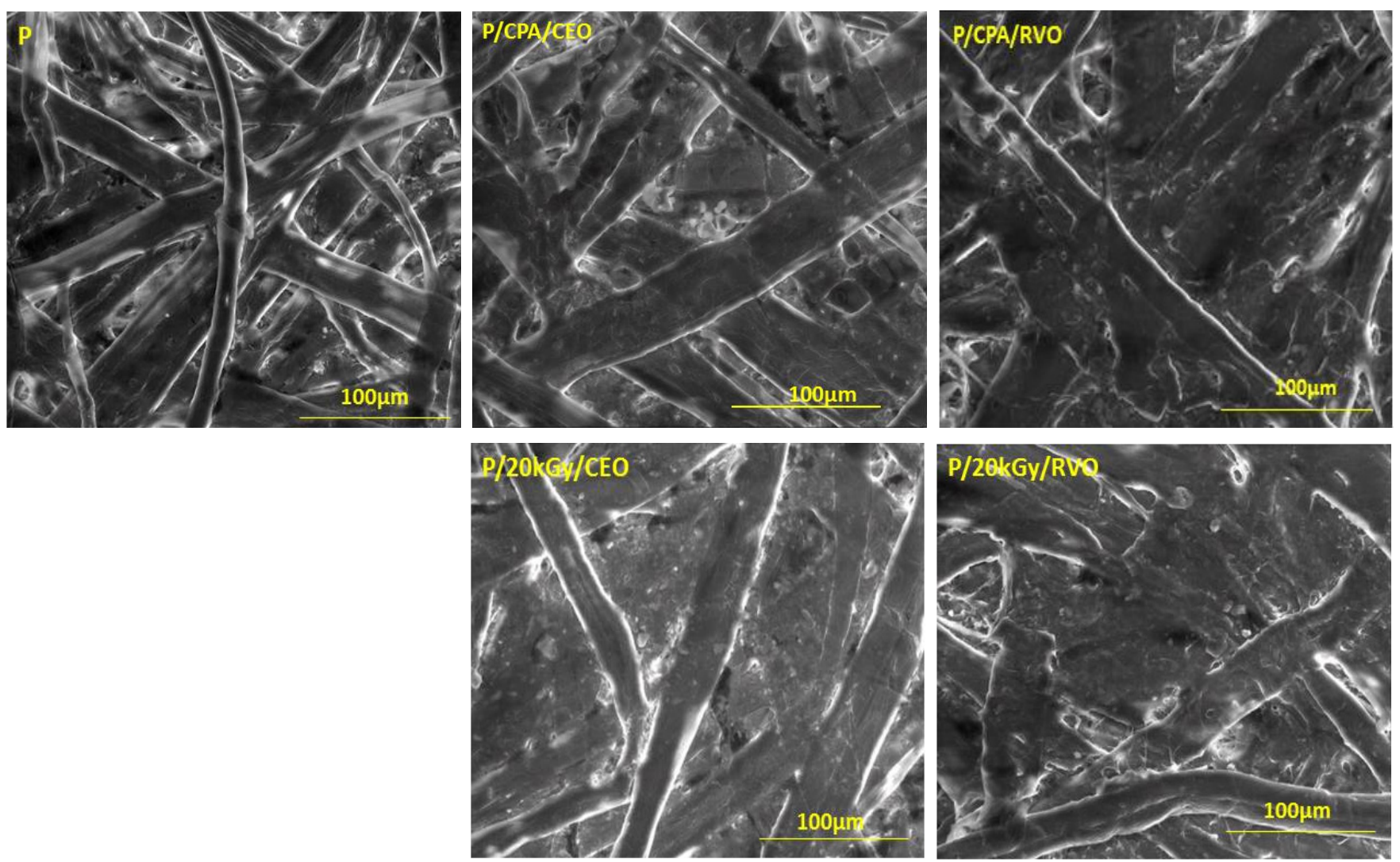

Figure 2. SEM images of the obtained samples.

The SEM image of untreated kraft paper showed that cellulose fibers are tied together and closely packed, forming a dense fiber matrix, with low porosity. Plant oils loading of kraft paper leads to increased homogeneity by entering into the pores. Therefore, the penetration of liquids, such as water into oil-loaded kraft papers is expected to be lower.

Information regarding the paper substrate modification is also given by the surface's elemental composition analysis. Table 2 summarizes the EDAX results for the modified samples compared with the unmodified one. 
Table 2. EDAX data expressed in weight (wt) and atomic (At) content for kraft paper treated with plant oils compared with the unmodified one.

\begin{tabular}{cccccccc}
\hline \multirow{2}{*}{ Sample } & \multicolumn{7}{c}{ Element } \\
\cline { 2 - 8 } & \multicolumn{2}{c}{ C } & & O & N & O/C \\
\cline { 2 - 8 } & wt $\%$ & At $\%$ & wt $\%$ & At $\%$ & wt $\%$ & At $\%$ & At $\%$ \\
\hline P & $59.87 \pm 1.20$ & $65.4 \pm 1.31$ & $38.29 \pm 0.77$ & $33.32 \pm 0.67$ & $0.79 \pm 0.02$ & $0.77 \pm 0.02$ & 0.509 \\
P/CPA & $54.24 \pm 1.08$ & $61.86 \pm 1.24$ & $41.58 \pm 0.83$ & $35.60 \pm 0.71$ & $0.87 \pm 0.02$ & $0.86 \pm 0.02$ & 0.575 \\
P/CPA/CEO & $53.28 \pm 1.07$ & $61.47 \pm 1.23$ & $44.51 \pm 0.89$ & $36.74 \pm 0.73$ & $1.81 \pm 0.04$ & $1.66 \pm 0.03$ & 0.597 \\
P/CPA/RVO & $55.87 \pm 1.12$ & $63.39 \pm 1.27$ & $42.59 \pm 0.85$ & $35.37 \pm 0.71$ & $1.33 \pm 0.03$ & $1.09 \pm 0.02$ & 0.558 \\
P/20 kGy & $53.39 \pm 1.07$ & $61.27 \pm 1.23$ & $41.25 \pm 0.83$ & $35.54 \pm 0.71$ & $0.91 \pm 0.02$ & $0.89 \pm 0.02$ & 0.580 \\
P/20 kGy/CEO & $54.60 \pm 1.09$ & $62.20 \pm 1.24$ & $42.08 \pm 0.84$ & $35.53 \pm 0.71$ & $1.99 \pm 0.04$ & $1.76 \pm 0.04$ & 0.571 \\
P/20 kGy/RVO & $56.39 \pm 1.13$ & $63.75 \pm 1.28$ & $39.33 \pm 0.79$ & $33.38 \pm 0.67$ & $2.42 \pm 0.05$ & $1.48 \pm 0.03$ & 0.523 \\
\hline
\end{tabular}

It appears that plasma treatment and especially the $\gamma$-irradiation significantly decreased the carbon content on the paper surface. The oxygen content was increased instead, leading to a higher $\mathrm{O} / \mathrm{C}$ atomic ratio, especially for $\gamma$-irradiation, which is more aggressive compared with plasma treatment. Nitrogen content also increased, being slightly higher for $\gamma$-irradiation, indicating that nitrogen from air was also involved in formation of reactive centers on paper surface. Both clove essential oil and rosehip vegetal oil contain carbon and oxygen in their molecules, but the carbon content is higher in vegetal oil due to substantial contribution of long aliphatic chains in fatty acids. The $\mathrm{O} / \mathrm{C}$ ratio in activated papers treated with plant oils decreased, especially after addition of the rosehip oil, indicating the fixation of tested oils onto the activated papers. Overall, the $\mathrm{O} / \mathrm{C}$ ratio increased after activation and addition of plant oils compared with the untreated paper, indicating an increased polarity due to the presence of oxygen containing groups in the composition of plant oils.

\subsection{Water Contact Angle}

Figure 3 presents the water contact angle of kraft paper modified with bioactive compounds. The untreated paper had a water contact angle of $96.6^{\circ}$, the observed hydrophobicity being, most probably, due to a pretreatment of the commercial packaging paper. Addition of plant oils strongly enhanced the hydrophobicity of the paper, the water contact angle considerably increasing to about $113^{\circ}$, with exception of the $\gamma$-irradiated sample treated with rosehip vegetal oil, which showed a slightly lower contact angle of $108^{\circ}$. This can be explained by the interactions that occur between the polar functional groups of the main compounds of vegetal oil (e.g., carboxyl) and the plasma and gamma irradiated paper, as revealed by FTIR spectroscopy, which lead to less available groups at the top surface to interact with water.

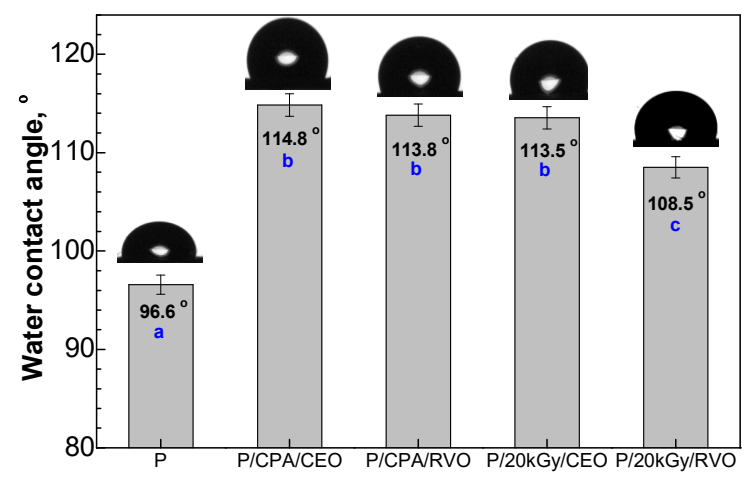

Figure 3. Water contact angle of kraft paper modified with vegetal oils. a-c Mean values with different letters indicate significant differences at $p<0.05$. 
The water contact angle values for all CEO modified samples were slightly higher compared with RVO modified samples. This can be attributed to the stronger interactions that occurred between the main compound of clove oil (eugenol) and kraft paper. Eugenol, being a molecule with a smaller chain than linoleic acid (main component in RVO), can create more intermolecular bonds with plasma or gamma radiation activated kraft paper, thus causing the decrease of the hydrophilic functional groups available on the surface of modified paper.

\subsection{Water Vapors Sorption}

Generally, the paper-based packaging materials absorb moisture from the surrounding media characterized by high level of humidity, mainly because they are composed of highly porous cellulose fibers with hydrophilic nature.

The sorption-desorption curves give information about the water vapor sorption mechanism and the interaction of packaging materials with water.

The uptake of water by kraft paper was analyzed as an adsorption process occurring in a porous medium. Water vapor is assumed to diffuse into the pore space and adsorbed onto the surfaces of the fibers constituting the paper sheet. The response of kraft paper to relative humidity variations was investigated.

Figure 4 presents the equilibrium moisture content (EMC) as a response to the relative humidity variations, at constant temperature $\left(25^{\circ} \mathrm{C}\right)$.

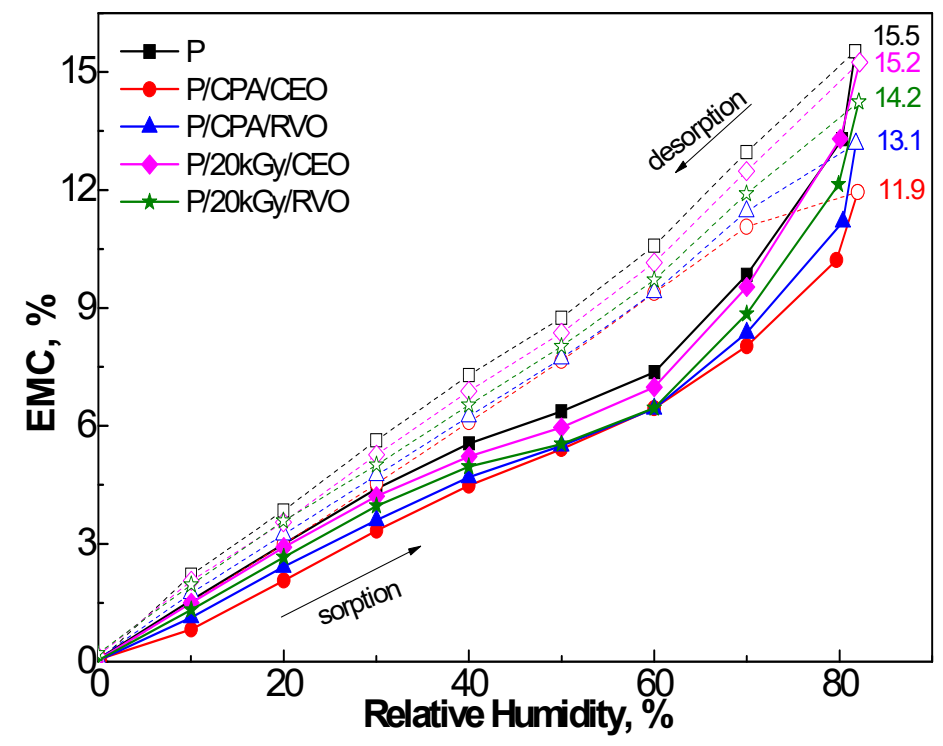

Figure 4. Sorption-desorption curves for analyzed samples.

According to the IUPAC classification [48], the physisorption isotherms can be associated to type IV curves, describing a mesoporous material. Sorption-desorption hysteresis phenomenon was observed, which is related with different behavior of the oil-loaded materials in various humidity conditions.

The EMC values decreased from $15.5 \%$ in unmodified kraft paper to $11.9 \%$ after modification with plant oils, indicating lower water adsorption (Figure 4). The EMC values for oil-loaded plasma treated samples are significantly lower than the ones corresponding to $\gamma$-irradiation, indicating higher hydrophobicity for the first ones. This outcome was also revealed by water contact angle measurements.

\subsection{DPPH Radical Scavenging Properties}

Reactions with DPPH radical were performed to asses if plant oils impart their antioxidant activity to the kraft paper on which they are immobilized (Table 3). 
Table 3. Values of DPPH half maximal Inhibitory Concentration (IC50) of oil-loaded paper samples.

\begin{tabular}{ccccc}
\hline Sample & CPA/CEO & CPA/RVO & 20 kGy/CEO & 20 kGy/RVO \\
\hline IC50 $(\mathrm{mg} / \mathrm{mL})$ & 0.052 & 14.190 & 0.104 & 35.475 \\
\hline
\end{tabular}

It appears that the paper substrate treated with clove essential oil have strong antioxidant activity, as indicated by the very low IC50 concentration. This is mainly due to eugenol and eugenol acetate compounds, which are the main components of clove essential oil and the main contributors to its total antioxidant activity [49]. The antioxidant activity of rosehip oil comes mainly from the radical scavenger compounds in the composition such as phenols, flavonoids, phenolic acids, anthocyanins and tannins, [16,50,51]. However, these are minor components compared with the fatty acids, which represent over $95 \mathrm{wt}$ $\%$ of the rosehip vegetal oil [52]. This explains the relatively lower antioxidant activity compared with clove essential oil. Similar results were obtained also in our previous study where argan oil was embedded into chitosan-based coating [36].

\subsection{In Vitro Antibacterial Activity}

Is well known that both plasma and gamma irradiation techniques are independently widely used in sterilization purposes in a diversity of applications, successfully inhibiting the microbial activity; being in the same time non-polluting, quite safe and simple methods.

Antibacterial tests were performed on three different bacteria which are important from the point of view of food safety, representing important food contaminants, namely Listeria monocytogenes (+), Salmonella enteritidis (-) and Escherichia coli (-)-Figure 5.

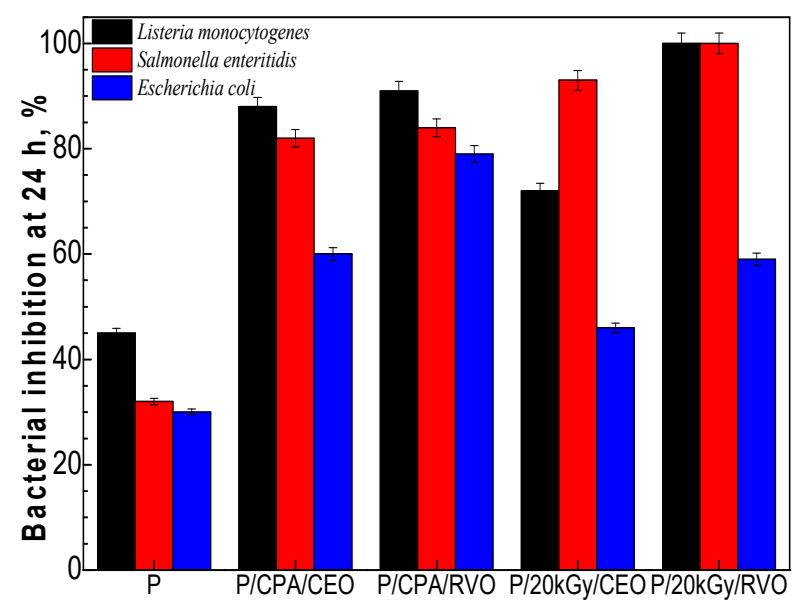

Figure 5. Variation of bacterial inhibition percentage determined for kraft paper modified by plant oils.

Taking into consideration the results presented in Figure 5, it can be said that addition of vegetal oils to kraft paper after plasma treatment or $\gamma$-irradiation significantly enhanced the bacterial inhibition at $24 \mathrm{~h}$ for tested gram positive and gram negative bacteria. Differences could be observed between the activation methods, plasma treatment inducing higher efficiency against Escherichia coli than $\gamma$-irradiation. The efficiency increased in the Escherichia coli $<$ Salmonella enteritidis $<$ Listeria monocytogenes order. $\gamma$-irradiation shifts the efficiency order, the bacterial inhibition for Salmonella enteritidis becoming higher than for Listeria monocytogenes. Differences could be also observed between the two plants oils, the rosehip vegetal oil showing higher bacterial inhibition compared with clove essential oil, for all tested bacterial strains. The stronger antimicrobial activity of RVO could be attributed to its more facile permeation into the bacterial cells membrane [53]. This outcome was also revealed by a study conducted by Assiri and Hassanien [54] where stronger antimicrobial activity was evidenced for the cold pressed clove oil than for clove essential oil. 
Overall, by adding bioactive plant oils onto kraft paper substrate, the strongest imparted effect on bacteria viability was noticed against Listeria monocytogenes and Salmonella enteritidis.

\subsection{In Vivo Microbiological Assesment on Food}

kraft The population of microorganisms related with cheese and meat spoilage after 24 and $48 \mathrm{~h}$, in terms of Total Viable Counts, is given in Figure 6.
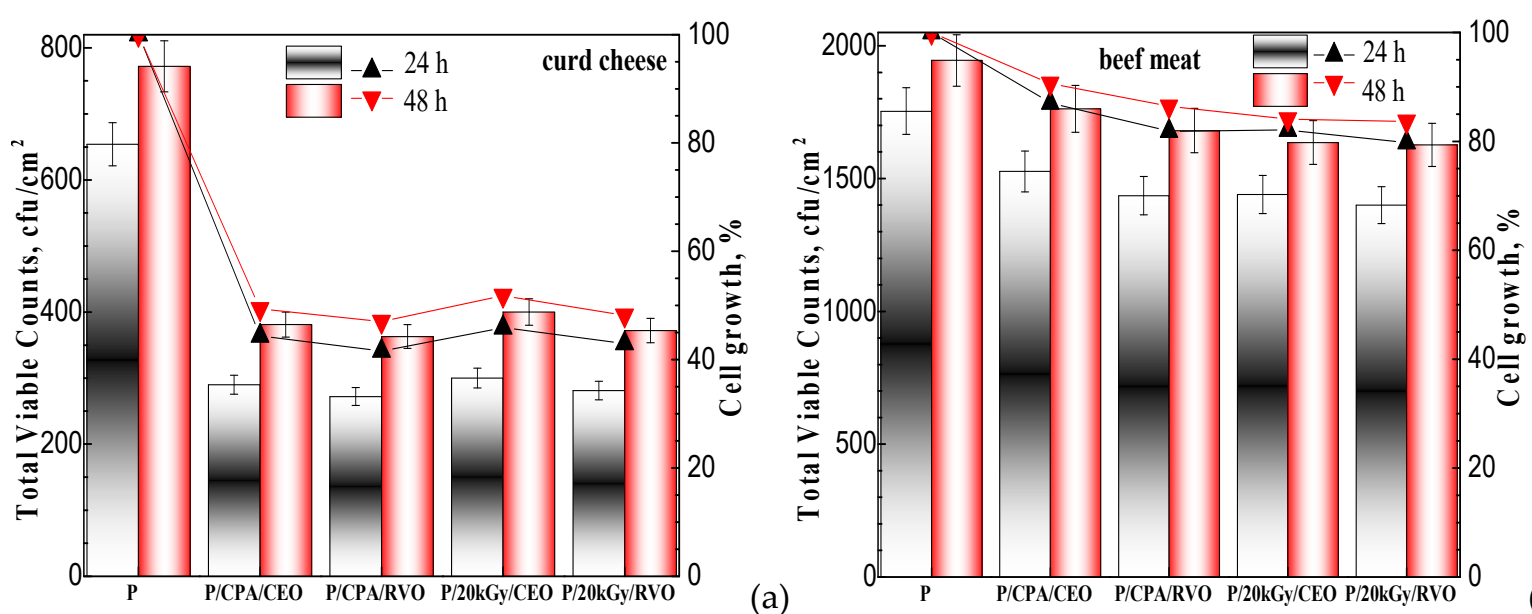

(b)

Figure 6. Total Viable Counts of untreated and of plasma activated or $\gamma$-irradiated followed by plant oils loading of kraft paper for fresh curd cheese (a) and fresh beef meat (b).

Modification of kraft paper with plant oils strongly decreased the microbial growth, both on fresh curd cheese and on fresh beef meat, as shown by the decrease of total viable count. Only small differences could be observed according to the activation method. The samples obtained by plasma treatment had slightly better inhibition effect on bacterial growth on cheese compared with those modified by $\gamma$-irradiation, while opposite was observed on beef meat, as evidenced from the values of percent cell growth relative with the unmodified kraft paper. Differences were also noticed between the two plant oils, the rosehip seeds vegetal oil having slightly better effect compared with clove essential oil.

It appeared that both plant oils showed good microbial inhibition on curd cheese, the cellular growth decreasing below $50 \%$ after $48 \mathrm{~h}$. However, the cellular growth remained high, above $80 \%$, for beef. These results may indicate that the tested kraft papers loaded with plant oils are more suitable for prolonging the preservation of foods with rather low initial bacterial content, such as fresh cheese. Higher amounts of plant oils would be needed to increase the efficiency against bacterial growth for foods with larger initial numbers of bacterial colonies, such as fresh raw beef meat products. However, attention should be paid on the fact that greater amounts of plant oils could negatively affect the organoleptic properties of foods.

Supplementary respirometry tests on fresh cheese were performed and showed that loading the kraft paper with the studied plant oils leads to lower oxygen consumption (Figure 7), which is related with inhibited biological processes of microbial growth. No clear differentiation could be observed between the two types of oils (essential and vegetal) or between the two types of physical activation (plasma or gamma irradiation) of paper, especially in the first two days of testing. The obtained respirometry results provide additional support for the potential use of oil loaded kraft paper as bioactive food packaging material. 


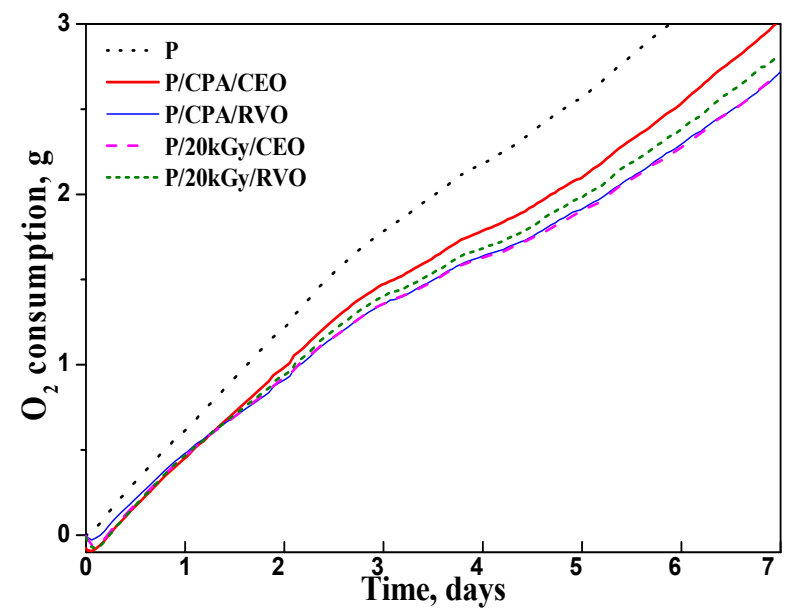

Figure 7. Time evolution of oxygen consumption during curd cheese storage in contact with kraft paper loaded with plant oils.

\section{Conclusions}

This study presented a way to impart bioactive properties to kraft cellulose paper by immobilization of antioxidant and antimicrobial plant oils, using cold plasma or $\gamma$ irradiation as substrate activation techniques. Structural and morphological properties of newly modified samples were strongly affected both by physical activation procedures and by oils loading, the changes being evidenced by ATR-FTIR and SEM-EDX data. Depending on the plant oil's type used, modified kraft paper presented different antibacterial and antioxidant properties. Essential clove oil induced higher antioxidant activity and better results for in-vivo antibacterial tests on fresh curd cheese and beef meat while cold pressed rosehip seeds oil was more effective for in-vitro tests on Listeria monocytogenes (+), Salmonella enteritidis (-) and Escherichia coli (-). The respirometry tests also supports the in vivo antimicrobial results, indicating that these materials could be promising for use in food industry to prolong food shelf-life.

Author Contributions: Conceptualization, A.I. and C.V.; Methodology, A.I. and C.V.; Formal analysis, A.I., E.S., A.B. and M.B.; Investigations, A.I., A.B. and M.B.; Resources, A.I., E.S., A.B., M.B. and C.V.; Data curation, A.I.; Writing—original draft preparation, A.I.; Writing-review and editing, E.S., M.B. and A.I.; Supervision, C.V. All authors have read and agreed to the published version of the manuscript.

Funding: This research was funded by IAEA Coordinated Research 17689-R0/2012 project.

Institutional Review Board Statement: Not applicable.

Informed Consent Statement: Not applicable.

Data Availability Statement: Not applicable.

Acknowledgments: Support from Emil Ghiocel Ioanid with access to plasma facility and from Traian Zaharescu for $\gamma$-irradiation. We thank Gina-Mihaela Pricope from Veterinary Laboratory and Food Safety, Food Safety Department, for performing the microbiological tests on fresh curd cheese and fresh beef meat.

Conflicts of Interest: The authors declare no conflict of interest.

\section{References}

1. Vasile, C.; Baican, M. Progresses in food packaging, food quality, and safety-Controlled-release antioxidant and/or antimicrobial packaging. Molecules 2021, 26, 1263. [CrossRef]

2. Coles, R. Introduction. In Food Packaging Technology; Coles, R., McDowell, D., Kirwan, M.J., Eds.; Blackwell Publishing: Boca Raton, FL, USA, 2003; pp. 1-31.

3. Nicoli, M.C. Shelf Life Assessment of Food, 1st ed.; CRC Press: Boca Raton, FL, USA, 2012.

4. Carocho, M.; Morales, P.; Ferreira, I.C. Natural food additives: Quo vadis? Trends Food Sci. Technol. 2015, 45, 284-295. [CrossRef] 
5. Becerril, R.; Nerín, C.; Silva, F. Encapsulation systems for antimicrobial food packaging components: An update. Molecules 2020, 25, 1134. [CrossRef] [PubMed]

6. Malhotra, B.; Keshwani, A.; Kharkwal, H. Antimicrobial food packaging: Potential and pitfalls. Front. Microbiol. 2015,6 , 611. [CrossRef] [PubMed]

7. Nešić, A.; Cabrera, G.; Dimitrijević-Branković, S.; Davidović, S.; Radovanović, N.; Delattre, C. Prospect of polysaccharide-based materials as advanced food packaging. Molecules 2019, 25, 135. [CrossRef]

8. Tayeb, A.H.; Tajvidi, M.; Bousfield, D. Paper-based oil barrier packaging using lignin-containing cellulose nanofibrils. Molecules 2020, 25, 1344. [CrossRef] [PubMed]

9. Techathuvanan, C.; Reyes, F.; David, J.R.D.; Davidson, P.M. Efficacy of commercial natural antimicrobials alone and in combinations against pathogenic and spoilage microorganisms. J. Food Prot. 2014, 77, 269-275. [CrossRef]

10. Tehrani, F.; Sadeghi, E. Effect of mint essential oil on growth of Listeria monocytogenes during the ripening and storage of Iranian white brined cheese. JAEBS 2015, 5, 150-154.

11. Goñi, P.; López, P.; Sánchez, C.; Gómez-Lus, R.; Becerril, R.; Nerin, C. Antimicrobial activity in the vapour phase of a combination of cinnamon and clove essential oils. Food Chem. 2009, 116, 982-989. [CrossRef]

12. Hu, Q.; Zhou, M.; Wei, S. Progress on the Antimicrobial Activity Research of Clove Oil and Eugenol in the food antisepsis field. J. Food Sci. 2018, 83, 1476-1483. [CrossRef]

13. Bentayeb, K.; Vera, P.; Rubio, C.; Nerin, C. The additive properties of oxygen radical absorbance capacity (ORAC) assay: The case of essential oils. Food Chem. 2014, 148, 204-208. [CrossRef]

14. Kumar, A.; Sharma, A.; Upadhyaya, K.C. Vegetable oil: Nutritional and industrial perspective. Curr. Genom. 2016, 17, 230-240. [CrossRef] [PubMed]

15. Qadir, R.; Anwar, F. Cold pressed rosehip seed oil. In Cold Pressed Oils: Green Technology, Bioactive Compounds, Functionality, and Applications, 1st ed.; Fawzy Ramadan, M., Ed.; Elsevier: London, UK, 2020; pp. 315-321.

16. Koczka, N.; Stefanovits-Bányai, E.; Ombódi, A. Total polyphenol content and antioxidant capacity of rosehips of some rosa species. Medicines 2018, 5, 84. [CrossRef]

17. Mármol, I.; Sánchez-De-Diego, C.; Jiménez-Moreno, N.; Ancín-Azpilicueta, C.; Rodríguez-Yoldi, M.J. Therapeutic applications of rose hips from different rosa species. Int. J. Mol. Sci. 2017, 18, 1137. [CrossRef] [PubMed]

18. Miklavčič, M.B.; Taous, F.; Valenčič, V.; Elghali, T.; Podgornik, M.; Strojnik, L.; Ogrinc, N. Fatty Acid Composition of cosmetic argan oil: Provenience and authenticity criteria. Molecules 2020, 25, 4080. [CrossRef]

19. Giuffrè, A.M.; Tellah, S.; Capocasale, M.; Zappia, C.; Latati, M.; Badiani, M.; Ounane, S.M. Seed oil from ten algerian peanut landraces for edible use and biodiesel production. J. Oleo Sci. 2016, 65, 9-20. [CrossRef]

20. Giuffrè, A.M.; Zappia, C.; Capocasale, M. Tomato seed oil: A comparison of extraction systems and solvents on its biodiesel and edible properties. Riv. Ital. Sostanze. Gr. 2017, 94, 149-160.

21. Musa, Ö. Nutrient composition of Rose (Rosa canina L.) seed and oils. J. Med. Food 2002, 5, 137-140.

22. Grajzer, M.; Prescha, A.; Korzonek, K.; Wojakowska, A.; Dziadas, M.; Kulma, A.; Grajeta, H. Characteristics of rose hip (Rosa canina L.) cold-pressed oil and its oxidative stability studied by the differential scanning calorimetry method. Food Chem. 2015, 188, 459-466. [CrossRef]

23. Man, A.; Santacroce, L.; Iacob, R.; Mare, A.; Man, L. Antimicrobial activity of six essential oils against a group of human pathogens: A comparative study. Pathogens 2019, 8, 15. [CrossRef]

24. Nazzaro, F.; Fratianni, F.; DE Martino, L.; Coppola, R.; De Feo, V. Effect of essential oils on pathogenic bacteria. Pharmaceuticals 2013, 6, 1451-1474. [CrossRef]

25. Butnaru, E.; Stoleru, E.; Brebu, M.A.; Darie-Nita, R.N.; Bargan, A.; Vasile, C. Chitosan-based bionanocomposite films prepared by emulsion technique for food preservation. Materials 2019, 12, 373. [CrossRef]

26. Ashfaq, A.; Clochard, M.-C.; Coqueret, X.; Dispenza, C.; Driscoll, M.S.; Ulański, P.; Al-Sheikhly, M. Polymerization reactions and modifications of polymers by ionizing radiation. Polymers 2020, 12, 2877. [CrossRef] [PubMed]

27. Muranyi, P.; Wunderlich, J.; Heise, M. Influence of relative gas humidity on the inactivation efficiency of a low temperature gas plasma. J. Appl. Microbiol. 2008, 104, 1659-1666. [CrossRef] [PubMed]

28. Jordá-Vilaplana, A.; Fombuena, V.; Garcia-Garcia, D.; Samper, M.D.; Sánchez-Nácher, L. Surface modification of polylactic acid (PLA) by air atmospheric plasma treatment. Eur. Polym. J. 2014, 58, 23-33. [CrossRef]

29. Sdrobiş, A.; Ioanid, G.E.; Stevanovic, T.; Vasile, C. Modification of cellulose/chitin mix fibers with N-isopropylacrylamide and poly(N-isopropylacrylamide) under cold plasma conditions. Polym. Int. 2012, 61, 1767-1777. [CrossRef]

30. Irimia, A.; Ioanid, G.E.; Zaharescu, T.; Coroaba, A.; Doroftei, F.; Safrany, A.; Vasile, C. Comparative study on gamma irradiation and cold plasma pretreatment for a cellulosic substrate modification with phenolic compounds. Radiat. Phys. Chem. 2017, 130, 52-61. [CrossRef]

31. Clegg, D.W.; Collyer, A. Irradiation Effects on Polymers; Elsevier: London, UK, 1991.

32. Yasser, F.H.A.; Amr El-Hag, A.; Ghada, F.E.M.; Reda, R. Gamma irradiation effect on the thermal stability, optical and electrical properties of acrylic acid/methyl methacrylate copolymer films. World J. Condens. Matter Phys. 2011, 1, 12.

33. Handayani, M.; Permawati, H. Gamma irradiation technology to preservation of foodstuffs as an effort to maintain quality and acquaint the significant role of nuclear on food production to Indonesia society: A Review. Energy Procedia 2017, 127, 302-309. [CrossRef] 
34. Drábková, K.; Ďurovič, M.; Kučerová, I. Influence of gamma radiation on properties of paper and textile fibres during disinfection. Rad. Phys. Chem. 2018, 152, 75-80. [CrossRef]

35. Stoleru, E.; Zaharescu, T.; Hitruc, E.G.; Vesel, A.; Ioanid, E.G.; Coroaba, A.; Safrany, A.; Pricope, G.; Lungu, M.; Schick, C.; et al. Lactoferrin-immobilized surfaces onto functionalized pla assisted by the gamma-rays and nitrogen plasma to create materials with multifunctional properties. ACS Appl. Mater. Interfaces 2016, 8, 31902-31915. [CrossRef] [PubMed]

36. Stoleru, E.; Vasile, C.; Irimia, A.; Brebu, M. Towards a bioactive food packaging: Poly(lactic acid) surface functionalized by chitosan coating embedding clove and argan oils. Molecules 2021, 26, 4500. [CrossRef] [PubMed]

37. Vasile, C.; Pâslaru, E.; Sdrobis, A.; Pricope, G.; Ioanid, G.E.; Darie, R.N. Plasma assisted functionalization of synthetic and natural polymers to obtain new bioactive food packaging materials in ionizing radiation and plasma discharge mediating covalent linking of stratified composites materials for food packaging. Available online: http://www-naweb.iaea.org/napc/iachem/ working_materials/F2-22063-CR-1-report.pdf (accessed on 22 September 2021).

38. Vasile, C.; Sivertsvik, M.; Mitelut, A.C.; Brebu, M.A.; Stoleru, E.; Rosnes, J.T.; Tănase, E.E.; Khan, W.; Pamfil, D.; Cornea, C.P.; et al. Comparative Analysis of the Composition and Active Property Evaluation of Certain Essential Oils to Assess their Potential Applications in Active Food Packaging. Materials 2017, 10, 45. [CrossRef] [PubMed]

39. Oniz-Magan, A.B.; Pastor-Blas, M.M.; Martin-Martinez, J.M. Different performance of $\mathrm{Ar}, \mathrm{O}_{2}$ and $\mathrm{CO}_{2}$ RF plasmas in the adhesion of thermoplastic rubber to polyurethane adhesive. In Plasma Processes and Polymers; D'Agostino, R., Favia, P., Oehr, C., Werheimer, M.R., Eds.; Wiley-VCH: Weinheim, Germany, 2005; pp. 177-192.

40. Rossi, D.; Pittia, P.; Realdon, N. Contact Angle Measurements and Applications in Pharmaceuticals and Foods: A Critical Review. In Progress in Adhesion and Adhesives; Mittal, K.L., Ed.; Scrivener Publishing LLC: Beverly, MA, USA, 2019; pp. 193-240. [CrossRef]

41. Odeyemi, O.A.; Alegbeleye, O.O.; Strateva, M.; Stratev, D. Understanding spoilage microbial community and spoilage mechanisms in foods of animal origin. Compr. Rev. Food Sci. Food Saf. 2020, 19, 311-331. [CrossRef] [PubMed]

42. SR ISO 4833/2014. Microbiology of the Food Chain-Horizontal Method for the Enumeration of Microorganisms; International Organization for Standardization: Geneva, Switzerland, 2014.

43. SR EN ISO 7218/2014. Microbiology of Food and Animal Feeding Stuffs-General Requirements and Guidance for Microbiological Examinations; International Organization for Standardization: Geneva, Switzerland, 2014.

44. Dorai, R.; Kushner, M.J. A model for plasma modification of polypropylene using atmospheric pressure discharges. J. Phys. D Appl. Phys. 2003, 36, 666-685. [CrossRef]

45. Kehrer, M.; Duchoslav, J.; Hinterreiter, A.; Mehic, A.; Stehrer, T.; Stifter, D. Surface functionalization of polypropylene using a cold atmospheric pressure plasma jet with gas water mixtures. Surf. Coat. Technol. 2020, 384, 125170. [CrossRef]

46. Rojas, J.; Cabrera, S.; Benavides, J.; Lopera, Y.; Yarce, C. Lipidic matrixes containing clove essential oil: Biological activity, microstructural and textural studies. Molecules 2021, 26, 2425. [CrossRef] [PubMed]

47. Mannozzi, C.; Foligni, R.; Scalise, A.; Mozzon, M. Characterization of lipid substances of rose hip seeds as a potential source of functional components: A review. Ital. J. Food Sci. 2020, 32, 721-733.

48. Cychosz, K.A.; Thommes, M. Progress in the physisorption characterization of nanoporous gas storage materials. Engineering 2018, 4, 559-566. [CrossRef]

49. El-Maati, M.F.A.; Mahgoub, S.; Labib, S.M.; Al-Gaby, A.M.; Ramadan, M.F. Phenolic extracts of clove (Syzygium aromaticum) with novel antioxidant and antibacterial activities. Eur. J. Integr. Med. 2016, 8, 494-504. [CrossRef]

50. Ilyasoğlu, H. Characterization of rosehip (Rosa canina L.) seed and seed oil. Int. J. Food Prop. 2014, 17, 1591-1598. [CrossRef]

51. Güney, M. Determination of fatty acid profile and antioxidant activity of Rosehip seeds from Turkey. Int. J. Agric. Environ. Food Sci. 2020, 4, 81-86. [CrossRef]

52. Jakovljevic, M.; Moslavac, T.; Bilic, M.; Aladic, K.; Bakula, F.; Jokic, S. Supercritical $\mathrm{CO}_{2}$ extraction of oil from rose hips (Rosa canina L.) and cornelian cherry (Cornus mas L.) seeds. Croat. J. Food Sci. Technol. 2018, 10, 197-205. [CrossRef]

53. Ramadan, M.F.; Asker, M.M.; Tadros, M. Lipid profile, antiradical power and antimicrobial properties of Syzygium aromaticum oil. Grasas y Aceites 2013, 64, 509-520. [CrossRef]

54. Assiri, A.M.A.; Hassanien, M.F. Bioactive Lipids, Radical Scavenging Potential, and Antimicrobial Properties of Cold Pressed Clove (Syzygium aromaticum) Oil. J. Med. Food 2013, 16, 1046-1056. [CrossRef] [PubMed] 